\title{
Implement the Harmonic Search Algorithm with Optimum Location of Capacitors Sizing and Dispatchable DGs to Control the Reactive Power on Interconnected Bus System
}

\author{
M. Suneetha ${ }^{1}$, R. Srinivasa Rao ${ }^{2}$, B. Subramanyam ${ }^{3}$ \\ ${ }^{1}$ Department of Electrical and Electronics Engineering, Narayana Engineering College, India \\ ${ }^{2}$ Department of Electrical \& Electronics Engineering, Jawaharlal Nehru Technological University College of \\ Engineering, India \\ ${ }^{3}$ Ex-Principal, Sri Venkateswara University College of Engineering, Tirupathi, India
}

\begin{abstract}
Article Info
Article history:

Received Jan 12, 2018

Revised May 13, 2018

Accepted May 27, 2018

Keyword:

Dispatchable DGs

Harmonic search algorithm

IEEE 30 bus

ABSTRACT

Power system is combination of generation, transmission and Distribution Network. In modern trends power system operation is very-difficulty due to energy storage elements, and variable inductive load. In power system, control the reactive power is essential to maintain the safe and more reliability of power system operation. In this paper, to organize the real power and reactive power by optimizing and sizing of capacitors and Dispatchable-Distribution generators in a distribution network with help of Harmonic Search Algorithm. The constraints of power system like voltage, real power and reactive and branch current carrying capacity are included in the evaluation of the objective function. To validate planned development network an IEEE 30 bus investigation system is considered.
\end{abstract}

Shunt capacitor

Copyright (c) 2018 Institute of Advanced Engineering and Science. All rights reserved.

\section{Corresponding Author:}

M. Suneetha,

Department of Electrical and Electronics Engineering,

Narayana Engineering College,

NH-5, Muthukur Road, A.K.Nagar, Near Apollo Hospital, Nellore, Andhra Pradesh-524 004, India.

Email: mogilikala.suneetha199@gmail.com

\section{INTRODUCTION}

In power system, the electrical power transfer from generation station to Distribution side through transmission line. But practically $100 \%$ power not transfer from generating station to distribution side due to inductive reactance. Some power stored in energy storage elements like inductance and capacitance effect of system. This power is known as storage power or reactive power. The inductive storage power controlled by using shunt capacitors, FACT devices like SVC, STATCOM and power electronic devices and Dispatchable Distribution Generators etc., The placing of capacitors are depends on the requirement of inductive reactive power which is a benefit to the system. But practically load is not constant on power system then always changes the reactive power on system.

Anwar.S.Siddique, MD.Farrukhrahman ${ }^{1}$ planned finest position of capacitors assignment on 10 bus radial distribution System by Using Fuzzy logic based technique to improve the voltage regulation and diminishing of energy loss. But drawback of Fuzzy system is very complex curse of dimensionality makes virtually impracticable in put into practice to set up a rule base with more than three inputs. M.Suneetha, R.SrinivasaRao ${ }^{2}$ projected a scheme of inductive reactive power organized by best sizing of capacitors with the help of Particle swarm optimization on IEEE 30 bus system. G.V.K.Murthy, S.Sivanagaraju3 intended to reduce the active power loss, voltage sag index improvement and total harmonic distortion by insertion the finest achievable sizing of DG unit with facilitate of Artificial Bee Colony (ABC) algorithm. 
K.Ravindra, R.Srinivasa Rao4 initiate a novel scheme for progress the profile of voltage on radial system, reconfiguration of the system by optimal locations for installation and 33-bus optimal locations for installation of DG units with help of Harmony Search algorithm on 69 bus and 33-bus Radial Distribution system. Duong Quoc Hung, N.Mithulananthan, Kwang Y.Lee5 presents a approach for minimize the energy losses per year by grouping of Dispatchable and non Dispatchable renewable distributed generation units. They conclude that maximum energy losses reduced by grouping of Dispatchable and non-Dispatchable DG units are better than non Dispatchable DG units on the distribution system.

T.D.Sudhakar, A.Vinoliyan6 focuses on power losses of overall system power by using optimum sizing of DG generators with facilitate of Big Bang Big Crunch algorithm on 33-bus distribution network and forward sweeper load flow method was used. Big Bang Big Crunch algorithm has elevated convergence speed and less computational time. Lucian loan Dulac, Mihali Abrudean and Dorn Bica7 describes to reduce the power losses distribution side of power system by using most favorable place of $2.3 \mathrm{MW}$ distributed generator in IEEE 14 Bus system with help of Neplan Software and used Newton Raphson extensivemethod.

S.Chandrasakhar, P.V.N.Prasad, and J.Laxmi8 presents to pick up the power quality on distribution side and recover the profile of voltage, at same time reduce the power losses by using best possible sizing of DGs with help of PSO on IEEE 30 bus system. Rashmi Priya, Surya Prakash9 projected decrease the losses of power by using most select distributed generation position in 16 bus distribution system with help of Genetic Algorithm and MATLAB software. The Position of DGs are also depends upon the time changeable loading circumstances and current situation of losses. GA advantage is they need no information concerning the response surface; they are opposed to flattering attentive in restricted optima and solve optimization troubles in power system.

In power system, load is not constant load in 24 hours. Depends upon load every time changes reactive power and real power losses. In order to reduce power losses, capacitors and dispatchable DG have to be installed. From reference papers observed that to reduce power losses at change of load, different DGs have to be installed in increases unit price cost. But in order to reduce unit price cost by installing capacitors with DG based upon the present situation of load. In this paper proposed to reduce the power losses and improve the profile of voltage by optimum sizing of DG units with help of HSA algorithm on 69 bus with help of Harmonic Search Algorithm and MATLAB.

\section{PROBLEM FORMULATION}

The Distribution system in general contains many number of buses, with each bus having number of parameters like bus voltage, current, impedance, real power and reactive power and power factor individually. The propose work to validate as taken IEEE 30 bus system as shown in Figure 1.

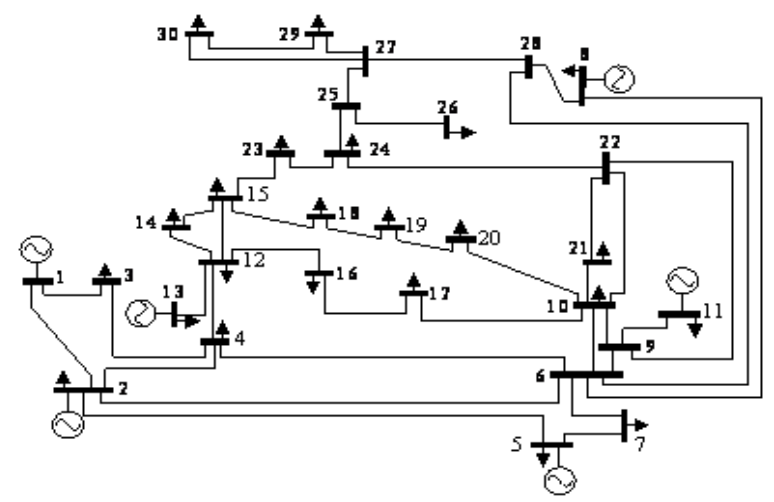

Figure 1. IEEE 30 bus system

Generally reactive power in the system have to be controlled according to the load demand and satisfying the following Equality and un equality constraints. The Equality constraints like balance equations of real and reactive power of all buses without slack bus as shown in (1-2). In Figure 2 is feeder line.

$$
\begin{aligned}
& \operatorname{Pg}_{\mathrm{j}}-\mathrm{Pd}_{\mathrm{j}}-\mathrm{v}_{\mathrm{i}}\left(\mathrm{g}_{\mathrm{ij}} \cos \theta_{\mathrm{ij}}+\mathrm{Bij} \sin \theta_{\mathrm{ij}}\right)=0 \\
& \mathrm{Q}_{\mathrm{g}} \mathrm{i}-\mathrm{Q}_{\mathrm{di}}-\mathrm{v}_{\mathrm{i}} \Sigma_{\mathrm{j} € \mathrm{~N}} \mathrm{v}_{\mathrm{j}}\left(\mathrm{g}_{\mathrm{ij}} \sin \theta_{\mathrm{ij}}+\mathrm{B}_{\mathrm{ij}} \cos \theta_{\mathrm{ij}}=0\right.
\end{aligned}
$$


Constraints of in equality are given below. On generator side, limits of reactive power is

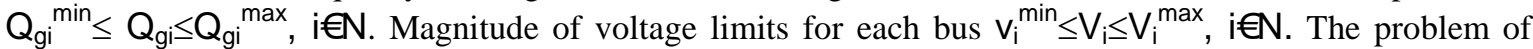
proposed network can be formulated to solve the function of fitness as shown in (3-5).

$$
\begin{aligned}
& \mathrm{P}_{\mathrm{i}+1}=\mathrm{P}_{\mathrm{i}}-\mathrm{P}-\mathrm{L}_{\mathrm{i}+1}-\mathrm{PLOSSi} \\
& =\mathrm{P}_{\mathrm{i}}-\left(\frac{\mathrm{R}_{\mathrm{i}}}{\left|\mathrm{V}_{\mathrm{i}}^{2}\right|}\left\{\mathrm{P}_{\mathrm{i}}^{2}+\left(\mathrm{Q}_{\mathrm{i}}+\mathrm{Y}_{\mathrm{i}}\left|\mathrm{V}_{\mathrm{i}}\right| 2\right) 2\right\}-\mathrm{P}_{\mathrm{Lk}+1}\right. \\
& \mathrm{Q}_{\mathrm{i}+1}=\mathrm{Q}_{\mathrm{i}}-\mathrm{Q}_{\mathrm{Li}+1}-\mathrm{QLossi} \\
& =\mathrm{Q}_{\mathrm{i}}-\frac{\mathrm{X}_{\mathrm{i}}}{\left|\mathrm{V}_{\mathrm{i}}^{2}\right|}\left\{\mathrm{P}_{\mathrm{i}}^{2}+\left(\mathrm{Q}_{\mathrm{i}}+\mathrm{Y}_{\mathrm{i} 1}|\mathrm{Vi}|^{2}\right)^{2}\right\}-\mathrm{Y}_{\mathrm{i} 1}\left|\mathrm{~V}_{\mathrm{i}}\right|^{2} \\
& \left|\mathrm{~V}_{\mathrm{i}+1}\right|^{2}=\left.\mathrm{V}_{\mathrm{i}}\right|^{2}-2\left(\mathrm{R}_{\mathrm{i}} \mathrm{P}_{\mathrm{i}}+\mathrm{X}_{\mathrm{i}} \mathrm{Q}_{\mathrm{i}}\right)+\frac{\mathrm{R}_{\mathrm{i}}^{2}+\mathrm{Q}_{\mathrm{i}}^{2}}{\left|\mathrm{~V}_{\mathrm{i}}^{2}\right|}\left(\mathrm{P}_{\mathrm{i}}^{2}+\mathrm{Q}_{\mathrm{i}}^{2}\right. \text { of shunt capacitors and DG on distribution side } \\
& =\mid V_{k}^{2}+\frac{R_{i}^{2}+X_{i}^{2}}{\left|V_{i}^{2}\right|}\left(\mathrm{P}_{\mathrm{i}}^{2}+\mathrm{Q}_{\mathrm{i}}+\mathrm{Y}_{\mathrm{i}}\left|\mathrm{V}_{\mathrm{i}}\right|^{2}\right)^{2}-2\left(\mathrm{R}_{\mathrm{i}} \mathrm{P}_{\mathrm{i}}+\mathrm{X}_{\mathrm{i}}\left(\mathrm{Q}_{\mathrm{i}}+\mathrm{Y}_{\mathrm{i}}\left|\mathrm{V}_{\mathrm{i}}^{2}\right|\right)\right)
\end{aligned}
$$

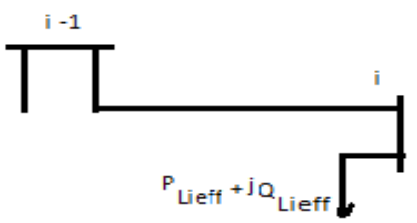

Figure 2. Feeder line

Compute power losses of line between $\mathrm{i}$ and $\mathrm{i}+1$ as shown in (6), total power loss of feeder as shown in (7) and DG and capacitor installation on bus of distribution system as shown in Figure 3.

$$
\begin{aligned}
& \mathrm{P}_{\text {Loss }}(\mathrm{i}, \mathrm{i}+1)=\frac{R_{i}\left(P_{i}^{2}+Q_{i}^{2}\right)}{\left|V_{i}^{2}\right|} \\
& \mathrm{P}_{\text {Tloss }}=\sum_{i=1}^{n} P_{\text {loss }(i, i+1)}
\end{aligned}
$$

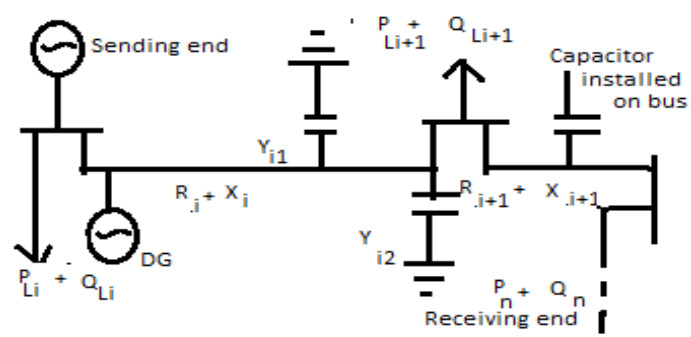

Figure 3. DG and capacitor installation on bus of distribution system

After installation of capacitors and DG on buses, more benefits such as power factor improvement, improving current carrying capacity and getting system more reliability and more efficiency and minimizing power losses as shown in (8-9).

$$
\begin{aligned}
& \mathrm{P}_{\text {capacitorloss }}=\frac{R_{i}}{V_{i}^{2}}\left(P_{i}^{2}+Q_{i}^{2}\right)+\frac{R_{i}}{V_{i}^{2}}\left(P_{G}^{2}+Q_{G}^{2}-2 P_{i} P_{G}-2 Q_{i} Q_{G}\right)\left(\frac{G}{L}\right) \\
& \mathrm{P}_{\text {loss }}^{\mathrm{DG}}=\frac{R j}{V_{j}^{2}}\left(P_{G}^{2}+Q_{G}^{2}\right)+\frac{R_{j}}{V_{j}^{2}}\left(P_{G}^{2}+Q_{G}^{2}-2 P_{j} P_{G}-2 Q_{j} Q_{G}\right)\left(\frac{G}{L}\right)
\end{aligned}
$$

Net reduction power loss as shown in (10) 


$$
\Delta P_{\text {loss }}=\frac{R_{i}}{V_{i}^{2}}\left(P_{G}^{2}+Q_{G}^{2}-2 P_{i} P_{G}+2 Q_{i} Q_{G}\right)\left(\frac{G}{L}\right)
$$

If $\Delta$ Power loss has positive sign than reduce the system losses with installation of DG other wise negative sign appears than high system losses maintain. The intention of the objective function of the problem is maximize the reduction of power losses in the system and satisfy the constraints as shown in (11).

$$
\text { Maximize } g=\max \left(\Delta \mathrm{P}_{\text {losses }}^{\text {capacitor }}+\Delta \mathrm{P}_{\text {loss }}^{\mathrm{DG}}\right)
$$

The installation of capacitors and DG is depend upon the sensitivity analysis as shown in (12).

$$
\mathrm{P}_{\text {Lieff }}=\frac{\left(\mathrm{P}_{\text {Lieff }}^{2}+\mathrm{Q}_{\text {Lieff }}^{2}\right) R_{\mathrm{i}}}{\mathrm{V}_{\mathrm{i}}^{2}}
$$

Obtain the loss sensitivity factor as shown in (13)

$$
\frac{\partial \mathrm{P}_{\text {line loss }}}{\partial \mathrm{P}_{\text {Lieff }}}=\frac{2 \mathrm{P}_{\text {Lieff }} \mathrm{R}_{\mathrm{i}}}{\mathrm{V}_{\mathrm{i}}^{2}}
$$

The installation of DG is based on LSFs.

\section{HARMONIC SEARCH ALGORITHM}

Harmonic search algorithm is primary intended by Geemet al in 2001. It has been functional to solve method of Harmony Search is provoked by the innovative main elites of the harmony in musical group of organization. The Best Harmony in nature particular correction between more than a few sound that have different frequencies. For example melody band improve rehearsal after preparation, when ever get pleasarable music then it is final harmony. The term harmony in music refers to the sound result caused from two or more instruments (popular decision variables) that plays a same time. Harmony evaluate the communication between two or more sound waves and their communication.

The new algorithm was enthused by the managing process that a accomplished musician follows when he is performance in a music band the following choice: First to play renowned apparently, every member of the band known the subject and can play it by heart i.e a pleasant music (solution of optimal problem). The function of fitness is determined by following steps in Harmonic search algorithm:

Step1: To set the problem, give parameters of algorithm and Specify the objective function. Initiate the algorithm parameters of HAS are Harmonic Memory(HM), Maximum iterations, maximum, Pitch adjustable rate(PAR), Harmony memory size(HMS) and stopping criterion NI and set of decision variables $\mathrm{x}_{1}, \mathrm{x}_{2}$, $\mathrm{x}_{3}, \ldots \ldots \mathrm{x}_{\mathrm{n}}$, where $\mathrm{x}$ have to be maintain within proper range $\mathrm{ximin} \leq \mathrm{xi} \leq \mathrm{ximax}$. Number of set of decision variables represented as $\mathrm{N}$, it is decided the HM matrix range harmony memory is store the all set of decision variable. Pitch adjustable rate and Harmony memory considering rate are used to develop the solution vector. Step2: To set the Harmony memory size this filled with decision variables.

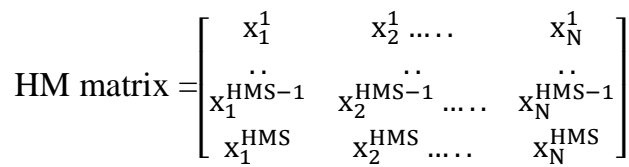

Step 3: New harmony have to be improvised. Determine the new harmony with help of

a. Pitch adjustable rate

b. Harmony memory

c. selection of variables randomly

Case(i): if random possible range values less than HMCR, the New harmony as taken from HM matrix other wise it worst harmony will be replaced by New harmony.

Case(ii): If HMCR is 0.75 indicates New harmony choose from old values which contain harmony memory with $75 \%$ probability otherwise $25 \%$ probability of new harmony generated by adjust the pitch adjustable rate and random selection variables. If random selection variables is maintain less than pitch adjustable rate then new harmony is given below:

xi1=old value xi \pm random selection variables.

Otherwise $x i 1=x i$ 
Case(iii): Suppose HMCR 0 and 1, then new harmony chosen from old values of Harmony memory range between 0 and 1 is taken as decision variables band width.

Step 4: Modernize the Harmony Memory If fitness of New Harmony x1 is better than old values in Harmony Memory than new harmony as taken in Harmony memory along with that worst old harmony which is presented in HM will be taken out.

Step 5: if reached optimum value New Harmony then Harmony Search algorithm is terminated otherwise repeat step 5 and 6.

\section{PRACTICAL IMPLEMENTATION OF HAS ALGORITHM FOR MINIMIZING POWER LOSSES IN IEEE BUS BY OPTIMAL LOCATING DG AND CAPACITORS INSTALLATION}

To validate proposed considered IEEE 30 bus system which has number of branches, number of feeders, line sectionalizing switches is shown in Figure 1. Here first select the candidate buses with open switches position. Calculate the sensitivity factor for candidate buses for present situation of real and reactive power losses which depend upon load. Then candidate buses have to be arranged in an order based on their sensitivity factors. The candidate bus which has more sensitivity then candidate buses are picked to Maintain capacitors and DG.

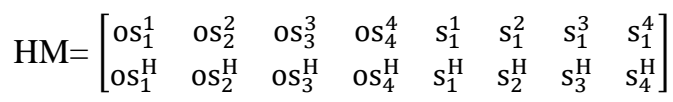

\section{CASE STUDY}

The proposed approach used NEWTON Raphson method to run optimum power flow along with Mat power version 12 and Mat power 5. MATLAB is a multi pattern numerical computing surroundings and a politeness any programming language improved by math works. The objective fuction is to minimize real power losses and reactive power losses in IEEE 30 bus system. in IEEE 30 bus, 4 generator buses, 22 load buses and number of feeders and line sectionlising switches are used.IEEE 30 bus system has superior reliability, it has number of generators units, back up power residue available in the event of one unit's breakdown. It has better power accessibility and redundancy. The generation capacity taken as 358.774 MW and reactive power is taken as 165.655 MVAR and gradually change the load, load real power is 333.4MW and load reactive power is 138.2MVAR. THE total power losses before optimization is 25.374 MW and 27.455 MVAR. The base case of voltage values of IEEE 30 bus system as shown in Table 1 and the base case of real and reactive power as shown in Table 2.

Table 1. Base data for Voltage:

\begin{tabular}{cccc}
\hline $\begin{array}{c}\text { Minimum Voltage } \\
\text { Magnitude (volts) }\end{array}$ & $\begin{array}{c}\text { Maximum Voltage magnitude } \\
\text { (volts) }\end{array}$ & $\begin{array}{c}\text { Minimum voltage Angle } \\
\text { degree }\end{array}$ & $\begin{array}{c}\text { Maximum voltage } \\
\text { Angle degree }\end{array}$ \\
\hline 0.95 p.u @PV \&PQ bus & 1.1 pu for PV bus 1.05 pu @ PQ bus & -17.81 deg@ bus 30 & 0.00 deg @ bus1 \\
\hline
\end{tabular}

Now optimize the objective function using Harmonic search algorithm, first given as initial parameter are set of decision variables $\mathrm{N}=9$, Harmonic memory considering rate $=0.85$, Harmony memory size $=20, \mathrm{Nmax}=20$, Pitch adjustable rate $=0.3$, the limits of Capacitors choosen for 0 to KW and DG is chosen from 0 to $2 \mathrm{MW}$.

Newton Raphson Method: The Aim of Newton Raphson power flow is to resolve the voltage magnitude in addition to angle at every one bus in the power system not including slack bus and Jacobean matrix by using Equations 1, 2 and 5 for IEEE bus system

Table 2. Base Data for Real Power and Reactive Power:

\begin{tabular}{cc}
\hline Maximum power Losses(MW) & Maximum Reactive power4 losses(MVAR) \\
\hline 18.3 MW @line 1-2 & 37.3 MVAR @ line 1-2 \\
\hline
\end{tabular}

\section{RESULTS AND MAIN BLOCK DIAGRAMS}

Figure 4 Harmonic Search Algorithm performance of Flow Chart are presented center, as shown below and cited in the manuscript.

Implement the Harmonic Search Algorithm with Optimum Location of Capacitors Sizing ... (M. Suneetha) 


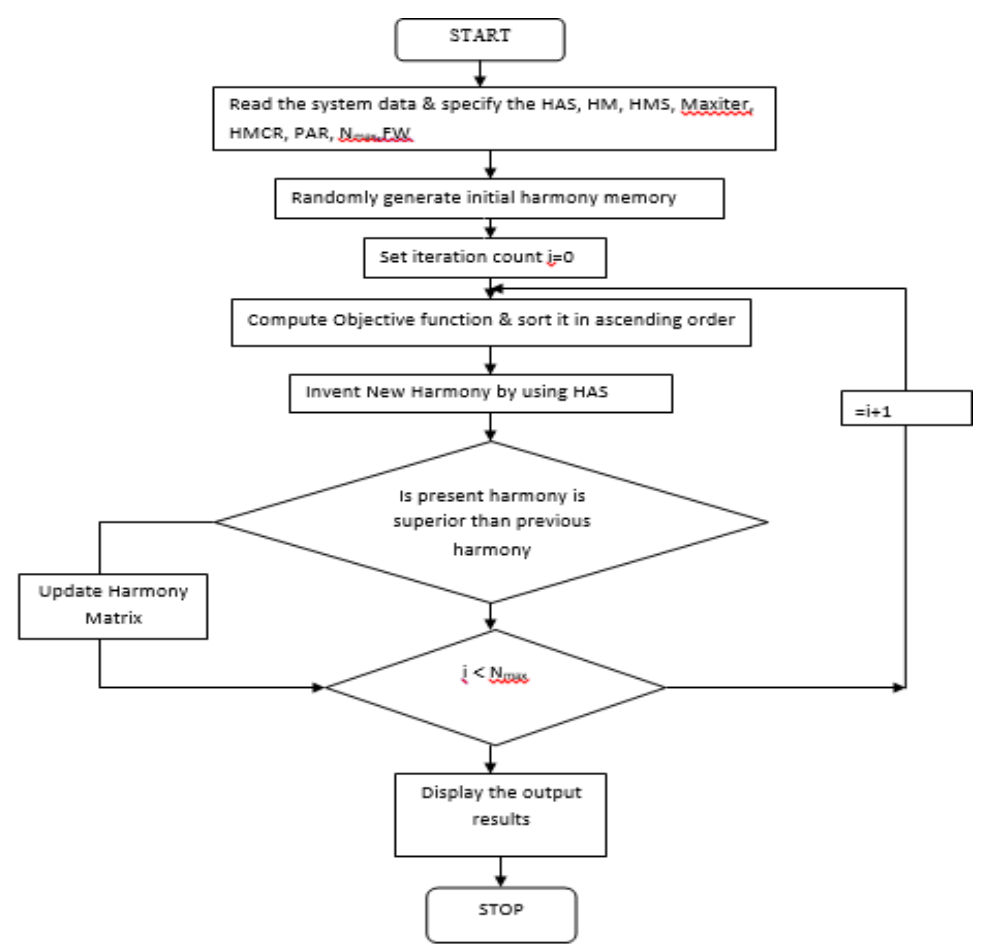

Figure 4. Harmonic search algorithm performance of flow chart

\subsection{Case for Before optimization of HAS:}

The details of Bus data, Load power, Generation power and each bus voltage magnitude and angle for before optimization as shown in Table 3. Tables Data For Load Bus, Generator Bus And Voltage In IEEE 30 System For Before Optimization Is Given Below are presented center, as shown below and cited in the manuscript.

Table 3. Data For Load Bus, Generator Bus And Voltage In IEEE 30 System For

\begin{tabular}{ccccccc}
\multicolumn{7}{c}{ Before Optimization (continue) } \\
\hline Branch & \multicolumn{2}{c}{ Voltage volts } & \multicolumn{2}{c}{ Load } & \multicolumn{2}{c}{ GENERATION } \\
\hline$\#$ & Mag(pu) & Ang(deg) & $\begin{array}{c}\text { Active } \\
\text { power } \\
\text { P(MW) }\end{array}$ & $\begin{array}{c}\text { Reactive } \\
\text { power } \\
\mathbf{Q}_{\mathbf{L}} \text { (MVAR) }\end{array}$ & $\begin{array}{c}\text { Real power } \\
\text { P }_{\mathbf{L}} \text { (MW) }\end{array}$ & $\begin{array}{c}\text { Reactive } \\
\text { power } \\
\mathbf{Q}_{\mathbf{L}} \text { (MVAR) }\end{array}$ \\
\hline 1 & & & 0.000 & 0.000 & 318.774 & 0.618 \\
2 & 1.060 & 0.000 & 12.700 & 40.000 & 50.000 \\
3 & 1.032 & -6.652 & 21.700 & 10.200 & 0.000 & 0.000 \\
4 & 0.999 & -11.682 & 17.600 & 1.600 & 0.000 & 0.000 \\
5 & 0.989 & -10.010 & 124.200 & 19.000 & 0.000 & 40.000 \\
6 & 1.000 & -13.583 & 0.000 & 0.000 & 0.000 & 0.000 \\
7 & 0.987 & -15.939 & 22.800 & 10.900 & 0.000 & 0.000 \\
8 & 1.001 & -14.366 & 30.000 & 30.000 & 0.000 & 40.00 \\
9 & 1.011 & -16.661 & 0.000 & 0.000 & 0.000 & 0.000 \\
10 & 1.036 & -18.266 & 5.500 & 2.000 & 0.000 & 0.000 \\
11 & 1.082 & -16.661 & 0.000 & 0.000 & 0.000 & 19.827 \\
12 & 1.051 & -17.510 & 11.200 & 7.500 & 0.000 & 0.000 \\
13 & 1.071 & -17.510 & 0.000 & 0.000 & 0.000 & 15.179 \\
14 & 1.036 & -18.415 & 6.200 & 1.600 & 0.000 & 0.000 \\
15 & 1.031 & -18.503 & 8.200 & 2.500 & 0.000 & 0.000 \\
16 & 1.038 & -18.105 & 3.500 & 1.800 & 0.000 & 0.000 \\
17 & 1.031 & -18.428 & 9.000 & 5.800 & 0.000 & 0.000 \\
18 & 1.021 & -19.124 & 3.200 & 0.900 & 0.000 & 0.000 \\
19 & 1.018 & -19.300 & 9.500 & 3.400 & 0.000 & 0.000 \\
20 & 1.022 & -19.099 & 2.200 & 0.700 & 0.000 & 0.000 \\
21 & 1.024 & -18.717 & 17.500 & 11.200 & 0.000 & 0.000 \\
22 & 1.024 & -18.702 & 0.000 & 0.000 & 0.000 & 0.000 \\
23 & 1.020 & -18.899 & 3.200 & 1.600 & 0.000 & 0.000 \\
24 & 1.013 & -19.078 & 8.700 & 6.700 & 0.000 & 0.000 \\
\hline & & & & & &
\end{tabular}


Table 3. Data For Load Bus, Generator Bus And Voltage In IEEE 30 System For Before Optimization (continue)

\begin{tabular}{ccccccc}
\hline Branch & \multicolumn{2}{c}{ Voltage volts } & \multicolumn{2}{c}{ Load } & \multicolumn{2}{c}{ GENERATION } \\
\hline$\#$ & Mag(pu) & Ang(deg) & $\begin{array}{c}\text { Active } \\
\text { power } \\
\text { P(MW) }\end{array}$ & $\begin{array}{c}\text { Reactive } \\
\text { power } \\
\mathbf{Q}_{\mathbf{L}} \text { (MVAR) }\end{array}$ & $\begin{array}{c}\text { Real power } \\
\mathbf{P}_{\mathbf{L}} \text { (MW) }\end{array}$ & $\begin{array}{c}\text { Reactive } \\
\text { power } \\
\mathbf{Q}_{\mathbf{L}} \text { (MVAR) }\end{array}$ \\
\hline 25 & 1.008 & -18.661 & 0.000 & 0.000 & 0.000 & 0.000 \\
26 & 0.990 & -19.089 & 3.500 & 2.300 & 0.000 & 0.000 \\
27 & 1.014 & -18.139 & 0.000 & 0.000 & 0.000 & 0.000 \\
28 & 0.998 & -14.241 & 0.000 & 3.000 & 0.000 & 0.000 \\
29 & 0.994 & -19.393 & 2.400 & 0.900 & 0.000 & 0.000 \\
30 & 0.982 & -20.293 & 10.600 & 1.900 & 0.000 & 0.000 \\
& Total & & 333.400 & 138.200 & 358.774 & 165.655 \\
\hline
\end{tabular}

\subsection{Case Ii}

Data for after optimization of proposed system by using harmonic search algorithm. Tables IEEE 30 bus system data after optimization are presented center, as shown below and cited in the manuscript as shown in Table 4.

Table 4. IEEE 30 Bus System Data After Optimization (continue)

\begin{tabular}{|c|c|c|c|c|c|c|c|}
\hline \multirow[t]{2}{*}{ S.No. } & \multicolumn{2}{|c|}{ Bus connection } & \multicolumn{3}{|c|}{ Data for line power } & \multicolumn{2}{|c|}{ Data for losses } \\
\hline & From & To & $\begin{array}{c}\text { Real } \\
\text { power } \\
\text { MW }\end{array}$ & $\begin{array}{c}\text { Reactive } \\
\text { power } \\
\text { MVAR }\end{array}$ & $\begin{array}{c}\text { Apparent } \\
\text { Power } \\
\text { MVA }\end{array}$ & $\begin{array}{c}\text { Real } \\
\text { power } \\
\text { MW }\end{array}$ & $\begin{array}{c}\text { Reactive } \\
\text { power } \\
\text { MVAR }\end{array}$ \\
\hline 1 & 1 & 1 & 318.774 & 0.648 & 318.775 & & \\
\hline 2 & 1 & 2 & 217.458 & -11.961 & 217.787 & 1.619 & 3.707 \\
\hline 3 & 1 & 3 & 101.316 & 12.610 & 102.098 & 0.844 & 2.610 \\
\hline 4 & 2 & 2 & 18.30 & 37.300 & 41.547 & - & - \\
\hline 5 & 2 & 1 & -209.364 & 30.497 & 211.573 & 1.619 & 3.707 \\
\hline 6 & 2 & 4 & 53.621 & 2.900 & 53,699 & 0.310 & 0.226 \\
\hline 7 & 2 & 5 & 103.340 & 5.913 & 103.509 & 0.952 & 3.233 \\
\hline 8 & 2 & 6 & 70.703 & -1.769 & 70.725 & 0.545 & 0.933 \\
\hline 9 & 3 & 3 & -12.400 & -10.200 & 16.056 & - & - \\
\hline 10 & 3 & 1 & -97.097 & 0.441 & 97.098 & 0.844 & 2.610 \\
\hline 11 & 3 & 4 & 84.697 & -10.497 & 85.345 & 0.190 & 0.389 \\
\hline 12 & 4 & 4 & -17.600 & -1.600 & 17.673 & - & - \\
\hline 13 & 4 & 2 & -52.071 & -1.770 & 52.101 & 0.310 & 0.226 \\
\hline 14 & 4 & 3 & -83.747 & 12.441 & 84.666 & 0.190 & 0.389 \\
\hline 15 & 4 & 6 & 73.545 & -22.816 & 77.002 & 0.141 & 0.328 \\
\hline 16 & 4 & 12 & 44.673 & -47.720 & 63.368 & 0.000 & 0.700 \\
\hline 17 & 5 & 5 & -124.200 & 21.000 & 125.963 & - & - \\
\hline 18 & 5 & 2 & -98.582 & 10.254 & 99.114 & 0.952 & 3.233 \\
\hline 19 & 5 & 7 & -25.618 & 11.328 & 28.010 & 0.076 & -0.140 \\
\hline 20 & 6 & 6 & 0.000 & 0.000 & 0.000 & - & - \\
\hline 21 & 6 & 2 & -67.978 & 6.435 & 68.282 & 0.545 & 0.933 \\
\hline 22 & 6 & 4 & -72.839 & 24.458 & 76.836 & 0.141 & 0.328 \\
\hline 23 & 6 & 7 & 49.449 & -0.854 & 49.456 & 0.131 & 0.109 \\
\hline 24 & 6 & 8 & 29.544 & -10.964 & 31.513 & 0.024 & -0.076 \\
\hline 25 & 6 & 9 & 27.547 & -30.821 & 41.338 & 0.000 & 0.491 \\
\hline 26 & 6 & 10 & 15.710 & -11.454 & 19.435 & 0.000 & 0.244 \\
\hline 27 & 6 & 28 & 18.576 & -7.779 & 20.139 & 0.012 & -2.252 \\
\hline 28 & 7 & 7 & -22.800 & -10.900 & 25.272 & - & - \\
\hline 29 & 7 & 5 & 25.995 & -12.026 & 28.643 & 0.076 & -0.140 \\
\hline 30 & 7 & 6 & -48.795 & 1.401 & 48.816 & 0.131 & 0.109 \\
\hline 31 & 8 & 8 & -30.000 & 10.000 & 31.623 & - & - \\
\hline 32 & 8 & 6 & -29.426 & 10.583 & 31.271 & 0.024 & -0.076 \\
\hline 33 & 8 & 28 & -0.574 & -0.264 & 0.631 & 0.000 & -0.749 \\
\hline 34 & 9 & 9 & 0.000 & 0.000 & 0.000 & - & - \\
\hline 35 & 9 & 6 & -27.547 & 33.278 & 43.201 & 0.000 & 0.491 \\
\hline 36 & 9 & 10 & 27.547 & 7.483 & 28.546 & -0.000 & 0.165 \\
\hline 37 & 9 & 11 & 0.000 & -19.129 & 19.129 & 0.000 & 0.140 \\
\hline 38 & 10 & 10 & -5.800 & 17.000 & 17.962 & - & - \\
\hline 39 & 10 & 6 & -15.701 & 12.676 & 20.676 & 0.000 & 0.244 \\
\hline 40 & 10 & 9 & -27.547 & -6.661 & 28.341 & -0.000 & 0.165 \\
\hline 41 & 10 & 17 & 5.156 & 4.15 & 6.618 & 0.003 & 0.007 \\
\hline 42 & 10 & 20 & 6.905 & 3.437 & 9.545 & 0.016 & 0.035 \\
\hline 43 & 10 & 21 & 15.776 & 9.971 & 18.663 & 0.023 & 0.049 \\
\hline 44 & 10 & 22 & 7.612 & 4.574 & 8.680 & 0.011 & 0.022 \\
\hline 45 & 11 & 11 & 0.000 & 19.827 & 19.827 & - & - \\
\hline
\end{tabular}

Implement the Harmonic Search Algorithm with Optimum Location of Capacitors Sizing ... (M. Suneetha) 
Table 4. IEEE 30 Bus System Data After Optimization (continue)

\begin{tabular}{|c|c|c|c|c|c|c|c|}
\hline \multirow[t]{2}{*}{ S.No. } & \multicolumn{2}{|c|}{ Bus connection } & \multicolumn{3}{|c|}{ Data for line power } & \multicolumn{2}{|c|}{ Data for losses } \\
\hline & From & To & $\begin{array}{c}\text { Real } \\
\text { power } \\
\text { MW }\end{array}$ & $\begin{array}{c}\text { Reactive } \\
\text { power } \\
\text { MVAR }\end{array}$ & $\begin{array}{c}\text { Apparent } \\
\text { Power } \\
\text { MVA }\end{array}$ & $\begin{array}{c}\text { Real } \\
\text { power } \\
\text { MW }\end{array}$ & $\begin{array}{c}\text { Reactive } \\
\text { power } \\
\text { MVAR }\end{array}$ \\
\hline 46 & 11 & 9 & -0.000 & 19.827 & 19.827 & 0.000 & 0.140 \\
\hline 47 & 12 & 12 & -11.200 & -7.500 & 13.479 & - & - \\
\hline 48 & 12 & 4 & -44.673 & 51.223 & 67.967 & 0.000 & 0.700 \\
\hline 49 & 12 & 13 & 0.000 & -14.898 & 14.898 & 0.000 & 0.056 \\
\hline 50 & 12 & 14 & 7,936 & 2.520 & 8.326 & 0.015 & 0.032 \\
\hline 51 & 12 & 15 & 18.108 & 7.296 & 19.522 & 0.046 & 0.090 \\
\hline 52 & 12 & 16 & 7.430 & 3.640 & 8.274 & 0.012 & 0.025 \\
\hline 53 & 13 & 13 & 0.000 & 15.179 & 15.179 & - & 0.032 \\
\hline 54 & 13 & 12 & -0.000 & 15.179 & 15.179 & 0.000 & 0.001 \\
\hline 55 & 14 & 14 & -6.200 & -1.600 & 6.403 & - & - \\
\hline 56 & 14 & 12 & -7.859 & -2.359 & 8.205 & 0.015 & 0.032 \\
\hline 57 & 14 & 15 & 1.659 & 0.759 & 1.824 & 0.001 & 0.001 \\
\hline 58 & 15 & 15 & -8.200 & -2.500 & 8.573 & - & - \\
\hline 59 & 15 & 12 & -17.879 & -6.847 & 19.145 & 0.046 & 0.090 \\
\hline 60 & 15 & 14 & -1.652 & -0.753 & 1.816 & 0.001 & 0.001 \\
\hline 61 & 15 & 18 & 6.138 & 1.869 & 6.417 & 0.008 & 0.017 \\
\hline 62 & 15 & 23 & 5.193 & 3.230 & 6.116 & 0.007 & 0.014 \\
\hline 63 & 16 & 16 & -3.500 & -1.800 & 3.936 & - & - \\
\hline 64 & 16 & 12 & -7.371 & -3.517 & 8.167 & 0.012 & 0.025 \\
\hline 65 & 16 & 17 & 3.871 & 1.717 & 4.235 & 0.003 & 0.006 \\
\hline 66 & 17 & 17 & -9.000 & -5.800 & 10.707 & - & - \\
\hline 67 & 17 & 10 & -5.142 & -4.115 & 6.586 & 0.003 & 0.007 \\
\hline 68 & 17 & 16 & -3.858 & -1.685 & 4.209 & 0.003 & 0.006 \\
\hline 69 & 18 & 18 & -3.200 & -0.900 & 3.324 & - & -- \\
\hline 70 & 18 & 15 & -6.097 & -1.785 & 6.352 & 0.008 & 0.017 \\
\hline 71 & 18 & 19 & 2.897 & 0.885 & 3.029 & 0.001 & 0.002 \\
\hline 72 & 19 & 19 & -9.500 & -3.400 & 10.090 & - & - \\
\hline 73 & 19 & 18 & -2.891 & -0.873 & 3.020 & 0.001 & 0.002 \\
\hline 74 & 19 & 20 & -6.609 & -2.527 & 7.076 & 0.003 & 0.007 \\
\hline 75 & 20 & 20 & -2.200 & -0.700 & 2.309 & - & - \\
\hline 76 & 20 & 10 & -8.825 & -3.260 & 9.408 & 0.016 & 0.035 \\
\hline 77 & 20 & 19 & 6.625 & 2.560 & 7.103 & 0.003 & 0.007 \\
\hline 78 & 21 & 21 & -17.500 & -11.200 & 20.777 & - & - \\
\hline 79 & 21 & 10 & -15.665 & -9.729 & 18.439 & 0.023 & 0.049 \\
\hline 80 & 21 & 22 & -1.837 & -1.471 & 2.353 & 0.000 & 0.000 \\
\hline 81 & 22 & 22 & 0.000 & 0.000 & 0.000 & - & - \\
\hline 82 & 22 & 10 & -7.558 & 8.778 & 8.778 & 0.011 & 0.022 \\
\hline 83 & 22 & 21 & 1.837 & 2.355 & 2.355 & 0.000 & 0.000 \\
\hline 84 & 22 & 24 & 5.721 & 6.456 & 6.456 & 0.009 & 0.014 \\
\hline 85 & 23 & 23 & -3.200 & -1.600 & 3.578 & - & - \\
\hline 86 & 23 & 15 & -5.158 & -3.159 & 6.049 & 0.007 & 0.014 \\
\hline 87 & 23 & 24 & 1.958 & 1.559 & 2.503 & 0.002 & 0.003 \\
\hline 88 & 24 & 24 & -8.700 & -2.400 & 9.025 & & \\
\hline 89 & 24 & 22 & -5.676 & -2.920 & 6.383 & 0.009 & 0.014 \\
\hline 90 & 24 & 23 & -1.950 & -1.543 & 2.487 & 0.002 & 0.003 \\
\hline 91 & 25 & 25 & -1.075 & 2.063 & 2.326 & 0.002 & 0.003 \\
\hline 92 & 25 & 25 & 0.000 & 0.000 & 0.000 & - & - \\
\hline 93 & 25 & 24 & 1.085 & -2.046 & 2.315 & 0.002 & 0.003 \\
\hline 94 & 25 & 26 & 3.545 & 2.368 & 4.264 & 0.009 & 0.014 \\
\hline 95 & 25 & 27 & -4.630 & -0.322 & 4.641 & 0.005 & 0.009 \\
\hline 96 & 26 & 26 & -3.500 & -2.300 & 4.188 & - & - \\
\hline 97 & 25 & 25 & -3.500 & -2.300 & 4.188 & 0.009 & 0.014 \\
\hline 98 & 27 & 27 & 0.000 & 0.000 & 0.000 & - & - \\
\hline 99 & 27 & 25 & 4.655 & 0.367 & 4.668 & 0.005 & 0.009 \\
\hline 100 & 27 & 25 & 4.655 & 0.367 & 4.668 & 0.005 & 0.009 \\
\hline 101 & 27 & 28 & -17.941 & 11.791 & 21.469 & 0.000 & 0.132 \\
\hline 102 & 27 & 29 & 6.192 & 1.674 & 6.415 & 0.018 & 0.033 \\
\hline 103 & 27 & 30 & 7.095 & 1.669 & 7.289 & 0.033 & 0.062 \\
\hline 104 & 28 & 28 & 0.000 & -3.000 & 3.000 & - & - \\
\hline 105 & 28 & 6 & -18.517 & -3.479 & 18.840 & 0.012 & -2.252 \\
\hline 106 & 28 & 8 & 0.576 & -3.482 & 3.529 & 0.000 & -0.749 \\
\hline 107 & 28 & 27 & 17.941 & -11.131 & 21.113 & 0.000 & 0.132 \\
\hline 108 & 29 & 29 & -2.400 & -0.900 & 2.563 & - & - \\
\hline 109 & 29 & 27 & -6.104 & -1.507 & 6.288 & 0.018 & 0.033 \\
\hline 110 & 29 & 30 & 3.704 & 0.607 & 3.754 & 0.007 & 0.013 \\
\hline 111 & 30 & 30 & -10.600 & -1.900 & 10.769 & - & - \\
\hline 112 & 30 & 27 & -6.930 & -1.357 & 7.061 & 0.033 & 0.062 \\
\hline 113 & 30 & 29 & -3.670 & -0.543 & 3.710 & 0.007 & 0.013 \\
\hline
\end{tabular}


Table 4. IEEE 30 Bus System Data After Optimization (continue)

\begin{tabular}{|c|c|c|c|c|c|c|c|}
\hline S.No. & \multicolumn{2}{|c|}{ Bus connection } & \multicolumn{3}{|c|}{ Data for line power } & \multicolumn{2}{|c|}{ Data for losses } \\
\hline & From & To & $\begin{array}{c}\text { Real } \\
\text { power } \\
\text { MW }\end{array}$ & $\begin{array}{c}\text { Reactive } \\
\text { power } \\
\text { MVAR }\end{array}$ & $\begin{array}{c}\text { Apparen } \\
\text { Power } \\
\text { MVA }\end{array}$ & $\begin{array}{c}\text { Real } \\
\text { power } \\
\text { MW }\end{array}$ & $\begin{array}{c}\text { Reactive } \\
\text { power } \\
\text { MVAR }\end{array}$ \\
\hline & & & 1 losses & & & 5.075 & 10.708 \\
\hline
\end{tabular}

In Figure 5 is real power losses in KW versus number of iterations. The optimization algorithm has placed four shunts such as three capacitors and one DG in buses 11, 18, 26 and 30 with values as shown in Table 5.

Table 5. Results of Optimization Algorithm has Placed Three Shunt Capacitors in Buses 11, 18, 26 and 30 with Values

\begin{tabular}{ccc}
\hline BUS & Capacitor Value in KVA & DG in MW \\
\hline 11 & 600 & - \\
18 & 550 & - \\
26 & 750 & - \\
30 & - & $1.2 \mathrm{MW}$ \\
\hline
\end{tabular}

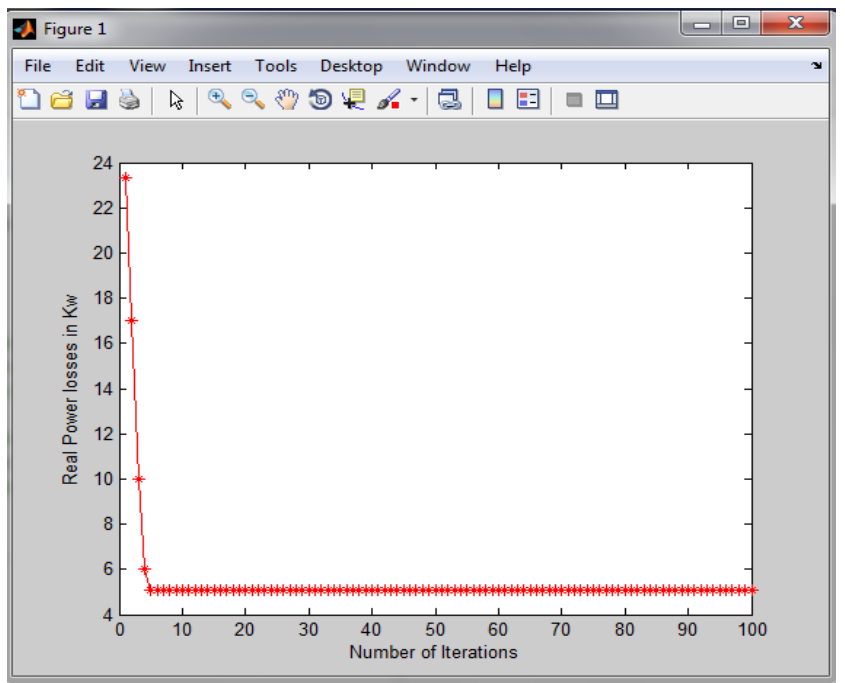

Figure 5. Curve for Number of iterations versus Real power losses in KW

\section{CONCLUSION}

In this paper, a new advance has been planned to reduce the real and reactive power losses by put in DG unit and capacitors on IEEE-30 bus system under varia-ble load condition by using Harmonic Search Algorithm Power losses vary with variation of load on the system. Capacitors and Dg installation is imitation to found the proposed method. The results show more effective in reducing power loss and improving voltage profile. Observation of references under load condition using more number of DGs which leads to high cost. In order to reduce cost instead of DGs, implemented optimum location sizing of capacitors and DG in which leads to low cost. The simulation results point to the fact that the losses can be reduced by the suitable location and sizing of the shunt devices and reduce the cost of unit.

\section{REFERENCES}

[1] S.Siddiqui, MD.Farrukh Rahman, “optimal capacitor placement to reduce losses in distribution system” WSEAS TRANSACTIONS ON POWER SYSTEMS E-ISSN-2224-350X17 Issue 1, volume 7, January 2012.

[2] Dr.R.Srinivasa Rao, Dr.B.Subramanyam, "Capacitor Sizing for Reactive Power Control by Using Particle Swarm Optimization”, International Research publication house, Paper code:15828ijee, 2015.

[3] G.V.K.Murthy, S.Sivanagaraju, S.Sstyanarayana, B.Hanumantha Rao E.W, "Optimal Placement of DG in Distribution System to Mitigate Power Quality Distrubances”, International journal of Electrical, computer, Energetic, Electronics and Communication Engineering Vol.7, No.2, 2013, World Academy of Science, Engineering and Technology verify the efficacy of the proposed method.

Implement the Harmonic Search Algorithm with Optimum Location of Capacitors Sizing ... (M. Suneetha) 
[4] R.Srinivasa Rao, K.Ravindra, k.Satish and S.V.I.Narasimham, "Powerm Loss Minimization in Distribution System Using Network Reconfiguration in the Presence of Distributed Generation”, Manuscript received October 09, 2011; revised February 23, 2012; accepted April 13, 1012. Date of publication May 30, 2012; date of current version January 17, 2013, paper no. TPWRS-009490-2011

[5] Duong Quoc Hung, N.Mothulananthan, Kwang .Y.Lee ,’Optimal Placement of Dispatchable and non Dispatchable Renewable DG Units in Distribution Networks for Minimizing Energy Loss”, School of Information Technology and Electrical Engineering, University of Queensland, Brisbane, QLD4072, Australia department of Electrical and computer Engineering, Baylor University, Waco , TX 76798-7356

[6] T.D.Sudhakar, A.Vinoliya, "Optimal DG Placement in Distribution Network Using Big Bang-Big Crunch Algorithm,” Science Technology Engineering and Management (ICONSTEM), Second International Conference on30-31 March 2016.

[7] Lucian loan Dulau, Mihail Abrudean, "Optimal Location of a Distributed Generator for Power Losses Systems. 2013; 9(1):1-12. Improvement,” doi:10.1016/j.protcy.2016.01.032, Author links open the overlay panel.

[8] S.Chandrashekhar Reddy, P.V.N.Prasad, A.Jaya Laxmi,” Optimal Number and Location of DGs to Improve Power Quality of Distribution System Using Particle Swarm Optimization,” International Journal of Engineering Research and Applications(IJERA) ISSN:2248-9622 www.ijera.com Vol.2, Issue 3, May- Jun 2012, pp.3077-3082.

[9] Rashmi Priya, Surya Prakash, "Optimal Location and Sizing of Generator in Distributed Generation system," International Journal of Innovative Research in Electrical, Electronics, Instrumentation and Control Engineering Vol.2, Issue 3, March 2014, copyright to IJIREEICE www,ijireeice,com.

\section{BIOGRAPHIES OF AUTHORS}

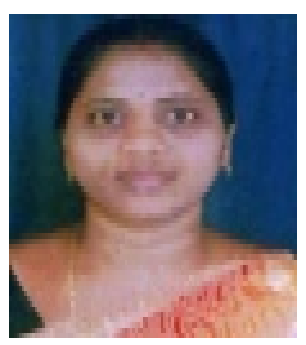

M. Suneetha, persuing Ph.D on JNTUK, Kakinada. She is working as a Associate Professor in Electrical \& Electronics Engineering in Narayana Engineering College in Nellore. She has more the 15 years experience in Teaching. She published 20 technical papers in National and International journals.

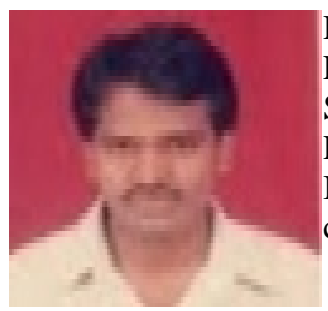

Dr.R. Srinivasa Rao is working as a Associate Professor in Electrical\&Electronics Engineering in JNTUCE, Kakinada. He is member of IEEE Professionals Bodies. Dr. Srinivasa Rao has more than 15 years experience in Teaching. He Guiding more 15 Ph.D Scholars. He published more than 42 technical papers in National and International journals and conferences. He got Research award from UGC. The award consists of 2 years and research grant of 3 lakhs.

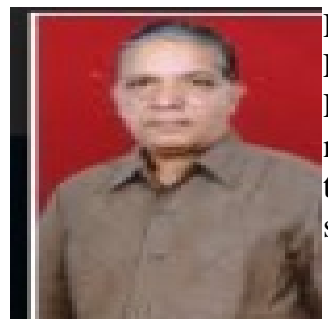

Dr.B.Subramanyam was working as Principal in S.V.University college of Engineering, Tirupathi. He has more than 35 years of experience in Teaching and Research. He held different positions in his career as Professor, Execute council member, convener for B.Tech in S.V.University college of Engineering. He had more than 35 years experience in Teaching and Research. He Guiding more than 27 Ph.D scholars. 